\title{
An IoT Based Intelligent Parking System for the Unutilized Parking Area With Real-Time Monitoring Using Mobile and Web Application
}

\author{
A. Z. M. Tahmidul Kabir ${ }^{1}$, Al Mamun Mizan ${ }^{2}$, Plabon Kumar Saha ${ }^{3}$, Md. Shajedul Hasan ${ }^{4}$, Mohitosh Pramanik ${ }^{5}$ \\ Department of Electrical and Electronic Engineering ${ }^{[1,2]}$, Department of Computer Science and Engineering ${ }^{[3]}$, Department of Computer \\ Engineering ${ }^{[4,5]}$ \\ American International University-Bangladesh \\ Dhaka-1229, Bangladesh \\ tahmidulkabir@gmail.com 1, almamuneee15@gmail.com²,pkumarsaha71@gmail.com², szdhasan71@gmail.com \\ mohitoshpm@gmail.com ${ }^{5}$
}

\begin{abstract}
The parking place number still remains insufficient despite the continuous growth in vehicle number. This study proposed a solution using modern technology to resolve these parking issues. The proposed solution is an automated parking management system that reduces parking scarcity by providing unused car parking places. This project has used IoT, mobile application, a web application to serve the following services, parking management, parking place availability monitorization, real-time invoice generation, payment system and, parking management. By proving this system, the hassle of people will be reduced as they are getting updates on nearby available parking spots. Alongside IoT, mobile application, web application other technologies such as GPS -GSM module, image processing method, and other technologies were integrated. The system offers both web and android app-based solutions for better customer experience and easy usage. Moreover, there is also an offline mode to use the system.
\end{abstract}

Keywords-Parking share, IoT system, Automated parking, Image processing, Android app. YOLOv3-tiny.

\section{INTRODUCTION}

As the global economy develops, the usage of vehicular transportation is also increasing day by day. For the need of frequent traveling, more and more people are choosing to have a personal vehicle which can have a significant impact on society. Though it can be convenient at a personal level, it can have an unfavorable impact on society. The impact is much more severe on the issue of parking. In major cities, the population is growing on a rapid scale, and so is the number of vehicles as more and more people are in an economic stage to afford a personal car. Car owners are facing a lot of hassle in finding parking spots. In megacities where the population is very large, it is more difficult to accommodate empty parking spots for every day a growing number of vehicles. Again there might be available parking positions, but for lack of getting available parking information, it doesn't reach the people. This case can mostly arise for residential parking places. It is shown in media that almost 15,000 new vehicles and 85,000 motorbikes are being registered every day in Dhaka city [1], [2]. According to 2019 statistics in India, 303,143.000-unit new vehicles were registered. This surpassed all preceding records [3]. Again statistics of 2017 in Pakistan indicate that there was a 9.7\% increase in new vehicle registration, and this number continues to rise each year [4], but despite the rapid increase, the number of parking spaces is not increasing to meet the growing demand. The situation is not very different in developed counties as well, where the general people struggle to find parking spots. For instance, in the USA, drivers spend an average of 17 hours every year to find empty parking spots. Again in Malaysia, drivers may have to wait up to 25 minutes to find an empty parking spot. Moreover, statistics show that $43 \%$ Nairobi (43 percent), $37 \%$ drivers in Milan, $44 \%$ in Bangalore (44 percent), and $58 \%$ drivers New Delhi (58 percent) have taken part in verbal abuse or picked a fight for occupying specific parking space [6]. These events cause congestion at parking lot's entry which eventually lead to jam in traffic as well.

Nowadays, IoT is a significant field as a research area. Various projects using IoT such as farming automation [7], home automation [8], etc. Following these, this project has also chosen IoT to design a parking solution that benefits both parking owners and car drivers. This smart system looks to find a nearby suitable parking spot for the drivers. The system has two modes such as online and offline mode. In the online mode, the user must have the application installed on the user's smartphone. The online mode covers various services or features such as the user can explore nearby parking spots, rent nearby parking lots, and choose the specific location of the user. The offline mode is generally designed for the user who has no smartphone or has no internet connection. The offline mode shows details of a parking spot such as rent rate, available parking spot from the display board situated near each parking place. With the help of the booking procedure, the user can select to book a parking spot. The system stores details like the number of entering exiting vehicles, compute the hourly bills for the lender. The system is suitable in all types of environments such as shopping malls, cinema halls, stadiums, offices, etc. The purpose of this system is to show the application users the available parking places in the area. Also, this avails the parking owner with the opportunity to earn from the parking lot. The system was designed using the following technologies like Arduino, raspberry pi 4, etc.

\section{BACKGROUND STUDY}

The authors of [9] proposed a smart parking management system containing RFID scanner, IR sensors, and mobile application. The system also introduces real-time driver interaction, car parking facilities, reduction of vacant space 
search, and parking time using a slot assignment technique. Authors of paper [10] introduced a parking system that uses low-cost IoT sensors, data aggregation for offering efficient routing for incoming vehicles to be parked. An algorithm called ADMM (Alternating Direction Method of Multipliers) was introduced by authors of [11], which balances the demand across multiple parking lots and deals with the cost minimization problem of parking assignment. The paper [12] proposed a parking management system that takes the environment, user, and devices into consideration and provides an optimal parking space to the driver using realtime information and availability. A smart parking platform was proposed by the authors of the paper [13] that uses an IoT-based system and mobile application. The modules in the system guide drivers to the parking place through the shortest route while protecting the vehicle from collision and displaying park reservation information. A parking system called Parking Rank was proposed by authors of [14]. It uses information regarding vacant parking lots, fair and service references to allocate parking space to oncoming vehicles. The IoT cloud-integrated smart parking system in the study [15] monitors vacant and occupied parking spaces, and drivers can use the web and mobile applications to prebook the vacant slots. A smart parking system called ASPIRE was suggested by the authors of [16] that consider driver's preferences of parking type, fare, and distance between destinations to the parking lot. With the help of IoT, vehicular network, GPS, and imaging system, the parking system assigns drivers with a preference-based optimal parking slot. A parking lot management system [17] suggested by researchers of Hohai University consists of different modules that handle parking information, fee and space management, allocation of a parking lot, and fee deduction, delivering information to the drivers, and storing parking lot data in administrator servers. The system was implemented using the Dijkstra and Floyd algorithm. The authors of [18] suggested an IoT-based E-parking prototype that performs parked vehicle detection and automated parking fee collection. It includes a local parking management system (LPMS) that consists of sensors and imaging modules and a central parking management system (CPMS) for performing wireless communication. The following paper [19] proposed a parking system algorithm that estimates parking traffic based on parking records history. With driver behavior analysis and parking traffic prediction, this system handles parking demands by allocating available parking lots with improved efficiency. The authors of [20] suggested a decentralized parking system that uses fog computing and IoT to provide parking services. The system validates real-world parking traffic with a characterized traffic using the 3D-Ray Launching (3D-RL) tool and provides parking services accordingly. The parking system suggested by the author of [21] contains agents for automated fee collection, vehicle entrance authorization, ticketing system, vacant lot detection, and modules like RFID, camera, identity \& subscription verification, etc. The system utilizes artificial intelligence and IoT, and with the help of preexisting agents, it authorizes parking spots according to individual driver's preferences. In the disabled parking system [22], the authors used modules like RFID, a variant of sensors, and cloud technology to confirm that the parking lots allocated for the disabled person are occupied only by the authorized people. The authors of [23] proposed a parking architecture that includes an eparking system and multi-agent features. The system contains facilities such as detecting vehicle entrance, vacant parking lot, vehicle guidance system, a smartphone application for booking parking space, and automated fee collection. The system uses RFID, ALPR for detection \& guidance systems, and multi-agents for handling booking, payment requests. The wireless parking system suggested by [24] uses microcontrollers, geomagnetic sensors, and NB wireless modules to find vacant parking slots by the magnetic field detection method. The microcontroller detects empty parking spaces with the help of algorithms. The following parking system in [25] uses IoT sensors and computer vision technology to monitor parking lots, count empty or occupied parked spaces. The system provides drivers with real-time parking space availability and occupancy prediction. The authors of the paper [26] introduced a parking system that tracks vehicle entry \& exit at the parking lot, scans license plates, and uploads parking data to the cloud database. The system utilizes an IoT cloud, image processing system, and programmable logic controller with different sensors, RFID scanners, and mobile applications for conveying information to drivers. The automobile parking system proposed in [27] determines the availability of parking space using sensors and, with the help of RFID modules, authorizes vehicles to use the vacant parking lot and has an automated payment system to deduct parking fees. The following paper [28] introduces an IoT distributed cloud architecture that improves search time of finding the nearest empty parking space based on road traffic. This parking system uses a road sensor unit and googles traffic services to collect real-time traffic data and an ant system algorithm to identify the optimal parking spot. The IoT parking system [29] proposed by researchers of Binus University utilizes sensors and cloud servers for monitoring real-time parking traffic, image processing for license plate checking, validates cars checking in \& checking out. It also comes with automated payment and parking spot reservation systems. In paper [30], Researchers of Christopher Newport University suggested a smart parking system that consists of a mobile application, machine learning, and a tracking system for the distribution and booking of parking spaces. The IoT parking monitoring system in paper [31] comes with a low-cost sensor system, including vehicle transceiver device sensors, motion detectors, global navigation satellite system sensors, and an automatic payment method. The following paper [32] suggests a smart parking system based on Bluetooth Low Energy (BLE). It comes with automated payment methods, a parking guidance system and mobile application for drivers, a database server for storing parking history, real-time usage, and parked vehicle metadata. An IoT cloud-platform-based parking system was proposed in paper [33] that accumulates data responsible for providing an efficient way of parking vehicles through using different sensors. The system delivers its end-user service through the web or mobile application. The parking system proposed by the authors of [34] utilizes IoT, artificial intelligence, and multi-agent systems. The agents are responsible for analyzing driver's parking preferences, vacant lot detection, guiding vehicles to the parking spot, vehicle identification and parking subscription validation, automated fee collection, and authorizing vehicle entrance. In the study [35], the problems with regular parking places were briefed. They have proposed an IoT-based parking solution that used technologies such as WIFI, RFID, IR sensors. Additionally, their system also provides an android application that can block parking slots for the user 
and calculate parking fees. In the developed system [36], the authors have introduced a pre-bookable parking system. In the proposed smart system, they have used Arduino, node MCU, to develop the system. The research [37] showcases the drawbacks of traditional parking systems and it's outcome. Because the number of vehicles is increasing, it's become troublesome to find parking slots. They have developed a system where they have used weighbridge load to implement IoT based smart parking system. In the paper [38], a parking lot monitoring system was introduced, which provides real-time parking lot's status about the empty parking spaces. They have used a deep learning method to identify the empty parking location from the frame captured by the camera in the parking lot. They have used mAlexNet to do the data per processing, camera adjustment, and detection works. The study [39] looks to solve the insufficient parking space solution by proposing an IoTbased parking system. The process used a GSM module for introducing a messaging system and provides information regarding free parking slots.

\section{METHODOLOGY}

The project is mainly a combination of two-part which are the electronic and software part. Both parts have a vital contribution to the development of the system. Both of the portions are combined to reach the final output. In the electronic part, the design, build, and testing of the functionality of the circuit was handled. Again, the software part is required for automatically managing the project. Every component is managed by programming. The whole system is an integrated system where the solution was assembled together using electronic circuits and software.

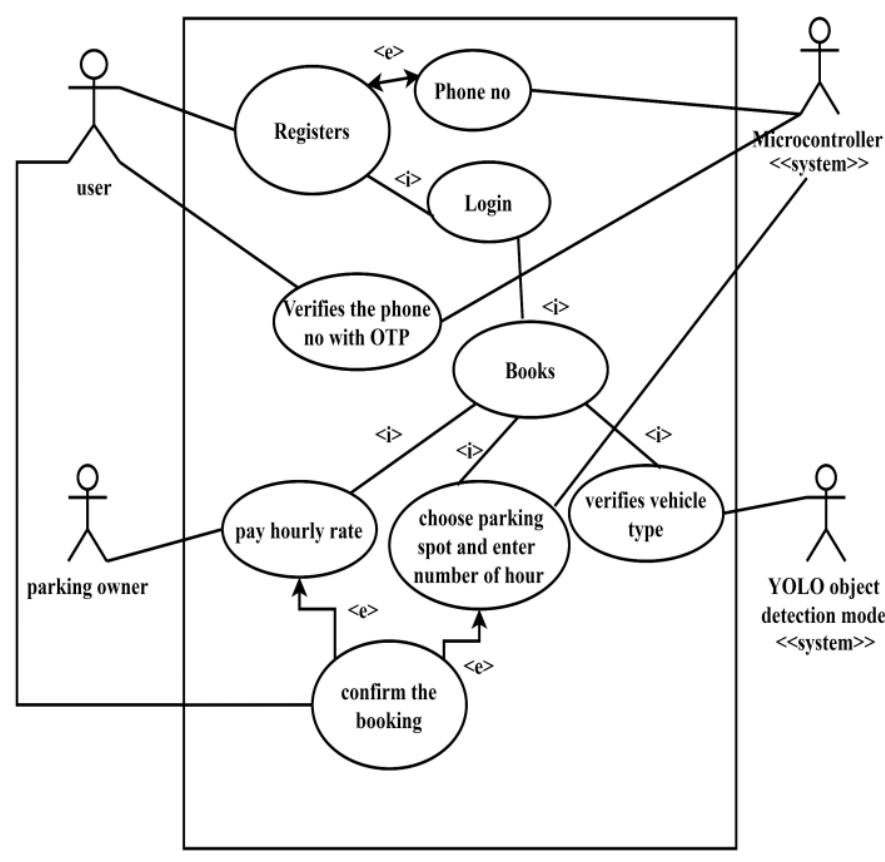

Fig. 1. Use case diagram.

\section{A. Use Case Diagram of This Project}

The entire solution is visualized in the above use case diagram (figure 1). To use the system, a user registers with their number, which is later verified by the system. Upon verification, the user logs into the system. After the login, the user can select a parking spot, and the vehicle type is verified by the YOLO object detection model. Upon successful verification, the user can choose a desirable parking spot, pays the owner, and inputs the number of hours to book the spot in order to finalize the booking.

\section{B. Image Processing for Vehicle Type Detection}

The incoming vehicles are recognized using Image processing. To identify the vehicle YOLOv3-tine model was trained. The YOLOv3-tiny algorithm was used for training the object detection model. YOLO is a popular deep learning-based object detection algorithm that is trained using the COCO dataset. The COCO data set contains 80 types of labeled objects. There are several kinds of object detection algorithms such as Histogram of Oriented Gradients (HOG), Single Shot Detector (SSD), YOLO (You Only Look Once) [40], Region-Based Convolutional Neural Networks (R-CNN), etc. Despite being very accurate RCNN is very slow. While SSD tends to be very fast, but the accuracy rate is dropped significantly. Now in terms of both speed and accuracy, YOLO is very accurate. This YOLO tiny v3 model is deployed in a Raspberry pi microprocessor. When the user provides a uniquely generated key for booking completion, the Raspberry pi takes an image of the customer vehicle. The car type is identified by the YOLOv3tiny model using the captured image. An output of a vehicle detection using the YOLOv3-tiny model was shown in Figure 1. The output also indicates the confidence rate of the detection, which is 0.9987 for the particular image.

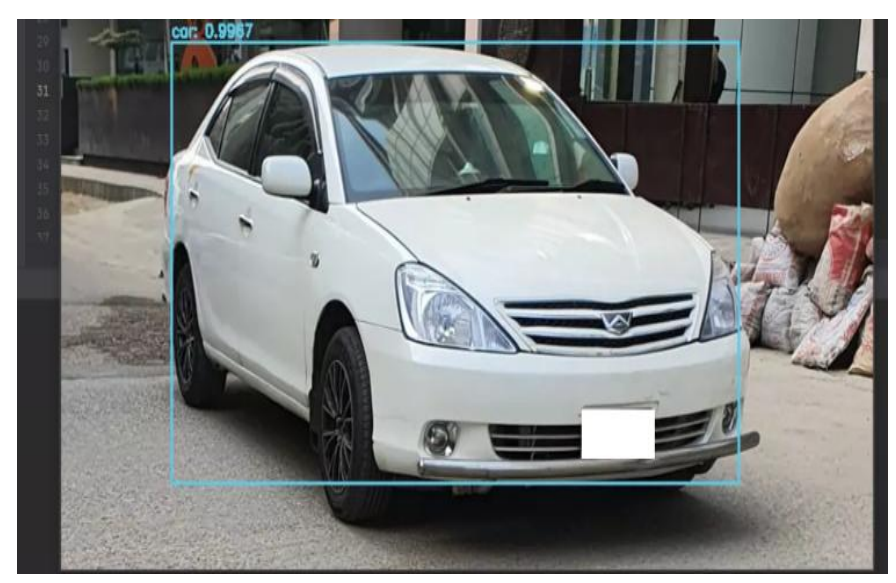

Fig. 2. Vehicle detection using YOLOv3-tiny.

TABLE I. YOLOv3-TINY MODEL EVALUATION CRITERIA

\begin{tabular}{|l|l|}
\hline Floating-point operations per second (FLOPS) & $5.56 \mathrm{Bn}$ \\
\hline Frames Per Second (FPS) & 220 \\
\hline mAp & $33.1 \%$ \\
\hline
\end{tabular}

\section{Offline Parking Mode}

Figure 3 visualizes the offline parking mode process. At the start of the offline mode (when the user has no previous account), the user must register in the system. When a user comes in front of the parking gate, the LCD displays a message "Do you want to park?" There is a keypad where the user can input yes to move forward. With the help of Raspberry $\mathrm{Pi}$, a microservice image of the vehicle is captured using the camera module. The Raspberry Pi model determines the vehicle type. Then the system wants to know the duration of the booking. Upon providing the data, the user is asked to enter their cell number where they receive a 
message with O.T.P. Using this O.T.P number, and the user can confirm the booking.

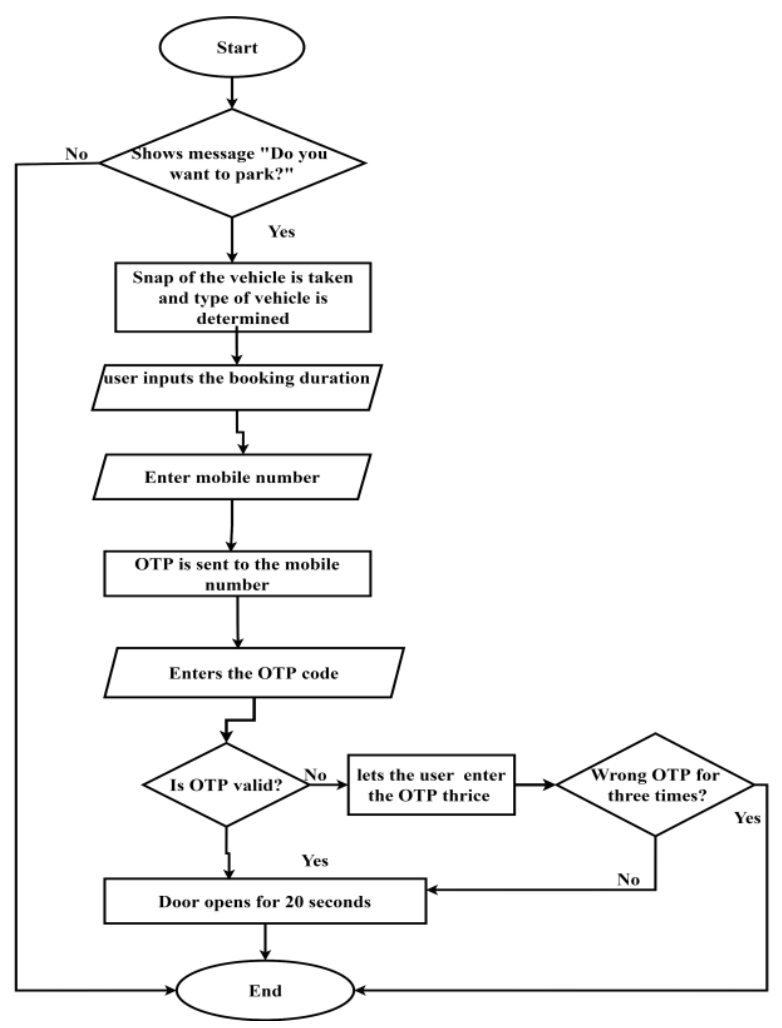

Fig. 3. Offline parking flow diagram.

\section{Prototype of This Project}

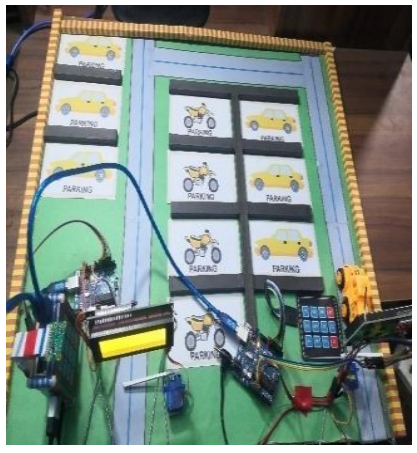

a

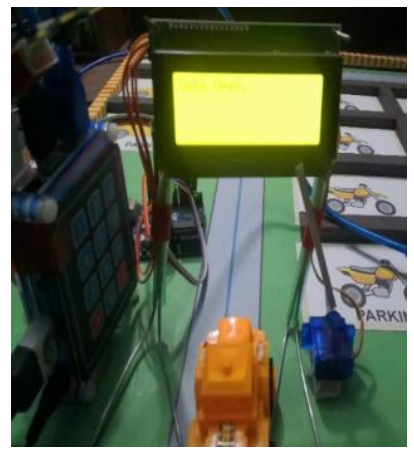

b
Fig. 4. (a) Prototype of the system, (b) vehicle entry.

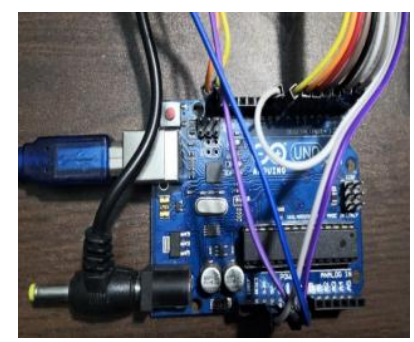

a

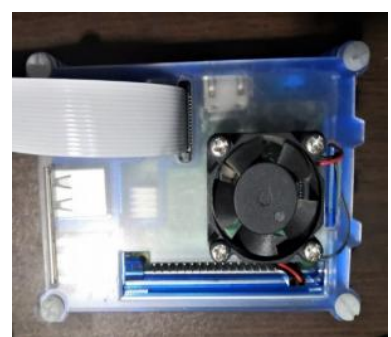

b
Fig. 5. (a) Arduino Uno \& (b) Raspberry Pi.

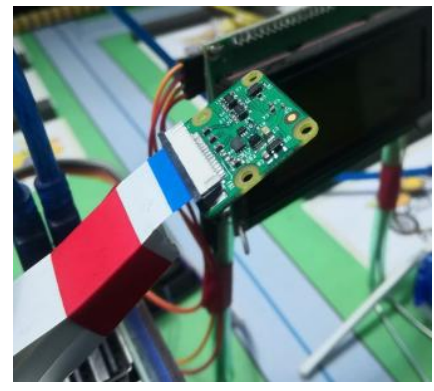

a

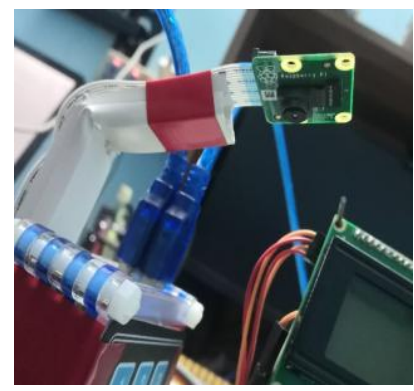

b

Fig. 6. Raspberry pi camera module (a) Top view (b) Bottom view.

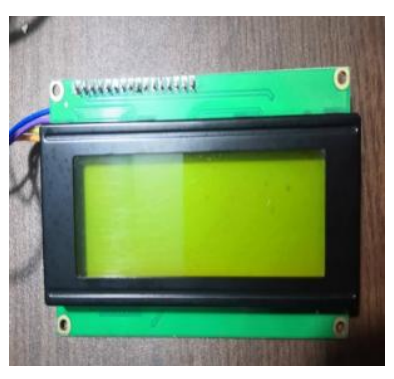

a

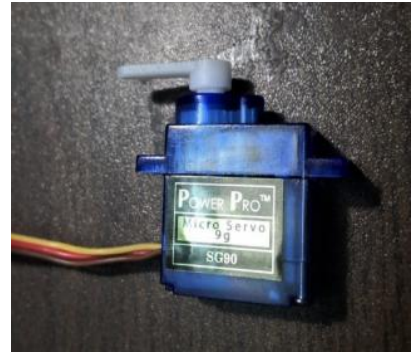

$\mathrm{b}$

Fig. 7. (a) 20x4 Character LCD \& (b) Servo Motor

\section{Monday, 11 Jan $\cdot 3: 28$ AM \\ Welcome to PAMS. Your OTP:} 6832

$$
\text { 8:49 AM }
$$

Welcome to PAMS. Your OTP: 9030

'10 Copy '9030'

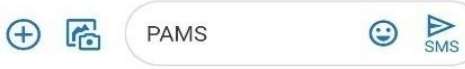

Fig. 8. One time password received by user.

Figures $4 \mathrm{a}$ and $4 \mathrm{~b}$ from the above images visualize the overall system prototypes. In the proposed intelligent parking solution, various components such as Arduino (figure 5a), Raspberry pi (figure 5b), Raspberry pi camera module (figure 6a, 6b), LCD display (figure 7a), servo motor (figure $7 \mathrm{a})$ etc., were used. In the figure 8 the OTP message from offline line mode was displayed.

\section{E. Web Application}

The web application of the system used C\# as server-side programming. For designing and performing client-side tasks HTML, CSS, Angular JS were used to create the web application. Using the web application, the parking lender can view the status of the parked vehicles. The lender can also view the duration of the parked vehicle, how much billing was generated, and other information. The web application is shown in figure 9. MS SQL Server database was used for the system. The database schema and values were visualized in Figures 10 and 11. 


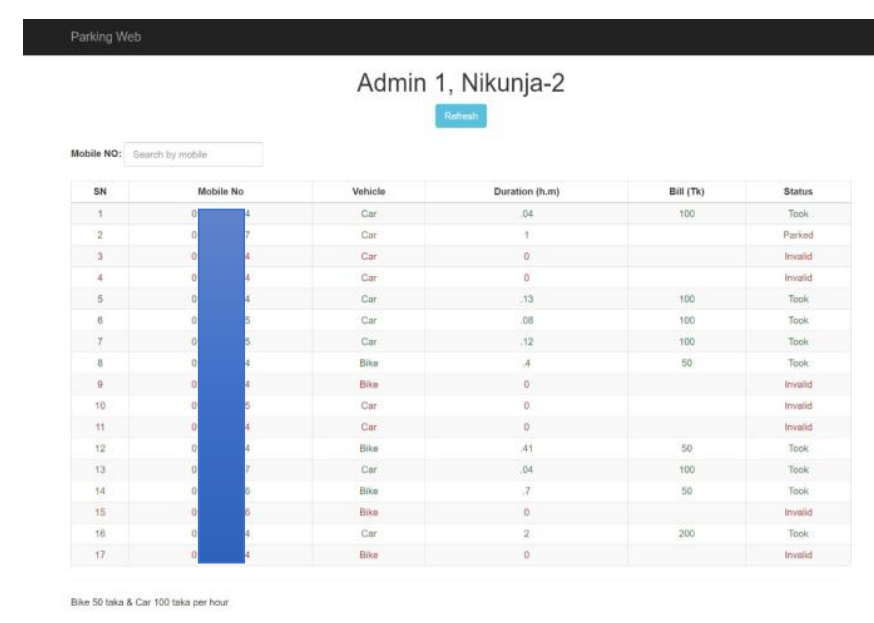

Fig. 9. Web application view.

\begin{tabular}{|l|l|l|}
\hline \multicolumn{1}{|c}{ Column Name } & \multicolumn{1}{c}{ Data Type } & Allow Nulls \\
\hline Id & int & \\
\hline Mobile & nvarchar(11) \\
\hline EntryOTP & int & \\
\hline StatusEnumld & int & $\square$ \\
\hline StartDate & datetime & $\square$ \\
\hline ExitOTP & int & $\square$ \\
\hline EndDate & datetime & $\square$ \\
\hline Bill & real & $\square$ \\
\hline VehicleTypeEnumld & int & $\square$ \\
\hline
\end{tabular}

Fig. 10. Database design view.

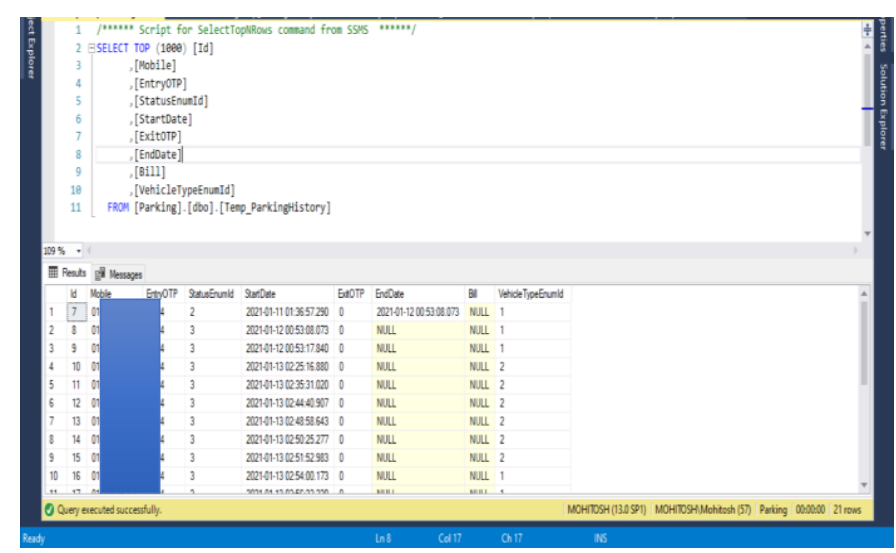

Fig. 11. Database select data view.

\section{F. Online Parking With Mobile Application}

The IoT device saves the following information such as available vehicle spots, vehicle type, an hourly rate of vehicle types, lender's mobile number, parking location, lender's address, and payment method. This information is saved in the firebase database. The system can provide a facility in both online and offline mode. In the online mode, the user can facilitate with both web and android mobile applications. They search and book parking spots from both the web and android app. To use the features from either web or android app, the user must register. During registration, the user must provide information such as mobile phone no, mobile payment method, password, and give permission to access geolocation. The geolocation is needed to get the user's current location so that the system can show them nearby available parking spots. The available parking spots are depicted as breadcrumbs on the map. This is shown in figure 9 (a). The application adds Google Maps API in the application and shows the breadcrumbs. A similar approach was taken by other previous projects to achieve this task [41] - [43]. To see parking details such as available parking spot, hourly rate as per vehicle type, specific address by clicking on each breadcrumb. The user must input vehicle type, booking duration to confirm the booking. Consequently, the user will get a unique code that will be used to verify the user on his chosen parking lot. After the code verification, the vehicle type is matched using image processing. Next, the charge will be calculated from the hourly rate and the number of hours the user has chosen to rent. The balance will be deducted from the user account and transferred to the parking owner account. The web application and the android application have exact parallel functionalities. Additionally, from figure 9(b), it is shown that the parking owner can choose to see the details of his parking lot using the admin dashboard.
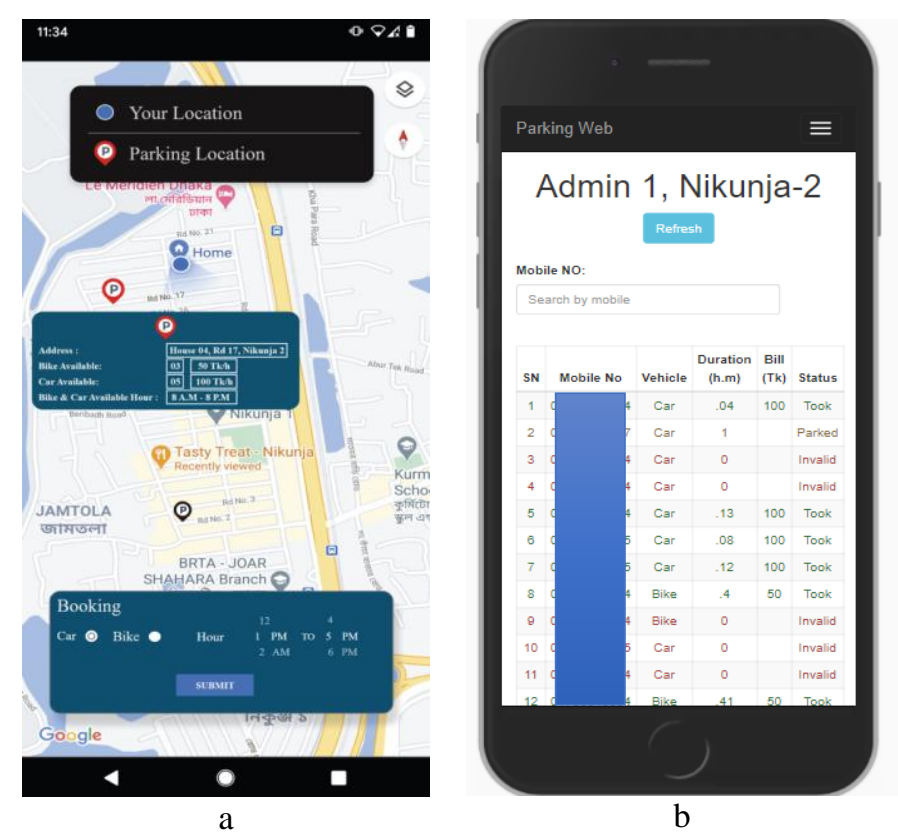

Fig. 12. (a) Parking lot booking through App, (b) Admin dashboard mobile view.

\section{Cost OF THE ProJect}

The cost details of the project are shown in the below table. While implementing the project in the real world, the cost may vary depending on the LCD display size and servo gate cost. To make the system totally automated, the parking lot owner has to integrate the servo gate. Else this cost will be reduced. Again, many commercial buildings and residential buildings have caretakers who can help maintain the offline mode if the servo gate is not integrated.

\begin{tabular}{|c|c|c|c|}
\hline No & Equipment & Quantity & Cost (USD) \\
\hline 1 & Raspberry Pi 4 & 1 & 110 \\
\hline 2 & Raspberry Pi Camera Module & 1 & 34 \\
\hline 3 & Arduino Mega & 1 & 9.5 \\
\hline
\end{tabular}




\begin{tabular}{|c|c|c|c|}
\hline 4 & GPS GSM GPRS SIM808 & 1 & 41.5 \\
\hline 5 & LCD display & 2 & 9.5 \\
\hline 6 & Servo Motor & 1 & 2 \\
\hline 7 & Keypad & 1 & 1.5 \\
\hline 8 & Power Supply & 2 & 3.5 \\
\hline 9 & Battery (4500mAh) & 1 & 39 \\
\hline & & Total & $\mathbf{\$ 2 5 0 . 5}$ \\
\hline
\end{tabular}

\section{THE NOBILITY OF THE WORK}

The presented system is totally an automated system. While the offline mode of the system may require some human supervision, the online mode is completely manless. The proposed system has both online and offline mode considering every case. In the online mode, the user can use the features of both web and android app to book the parking spot by choosing from the nearby available spots. While selecting a suitable position, they can see the details such as available spots, pricing of each of the parking spaces. Again the offline mode lets the user book a spot very conveniently. The system tries to provide a simple automatic parking providing solution. Additionally, the system benefits the parking spot lenders as they can collect money from every booking where previously the parking facilities might have been underutilized.

\section{CONCLUSION}

The project looked to solve a growing issue that was especially very necessary for the cities while modern technology. Evidently, the cities are facing many problems because of lacking parking places. Many times the parking scarcity arises from not knowing about available empty parking spots. So many times, the roadsides space are being used as a parking spot, resulting in a traffic jam, which is already another issue in cities. So many times, parking on the road is not allowed. So for not knowing or finding a place to park, they face a lot of hassle on a regular basis. This proposed system looks to solve these issues by finding the car owners suitable parking spots. Moreover, the parking lenders are also benefited because of the rent they are getting from lending their unutilized parking spots. The system helps the mass people in large cities by providing them required parking spots hassle-free. Additionally, the system is very reasonably priced to implement and creates a chance to utilize the empty space of the parking space lenders.

\section{REFERENCES}

[1] "Chaos on road due to inadequate parking space." [Online]. Available: https://www.newagebd.net/article/98843/chaos-on-roaddue-to-inadequate-parking-space. [Accessed: 23-Feb-2021].

[2] A. Kibria, "Addressing problem of car parking," The Financial

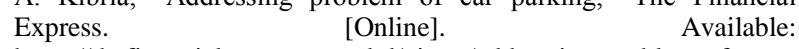
https://thefinancialexpress.com.bd/views/addressing-problem-of-carparking-1555686704. [Accessed: 23-Feb-2021].

[3] "India: Number of Registered Motor Vehicles: CEIC," Global Economic Data, Indicators, Charts \&amp; Forecasts. [Online]. Available: https://www.ceicdata.com/en/india/number-of-registeredmotor-vehicles. [Accessed: 23-Feb-2021].

[4] "Registered vehicles in Pakistan increased by $9.6 \%$ in 2018," Profit by Pakistan Today, 16-Jun-2019. [Online]. Available: https://profit.pakistantoday.com.pk/2019/06/16/registered-vehicles-inpakistan-increased-by-9-6-in-2018/. [Accessed: 23-Feb-2021].
[5] S. Gautam, R. Pansare, A. Chaudhary, and K. Gupta, "People In Kuala Lumpur Waste 25 Minutes Every Day Looking For Parking," Get My Parking Blog, 27-Mar-2020. [Online]. Available: https://blog.getmyparking.com/2020/03/04/people-in-kuala-lumpurwaste-25-minutes-every-day-looking-for-parking/. [Accessed: 28Feb-2021].

[6] E. T. Bureau, "Two Indian cities New Delhi, Bangalore have most parking woes in the world: Survey," The Economic Times, 29-Sep2011. [Online]. Available: https://economictimes.indiatimes.com/twoindian-cities-new-delhi-bangalore-have-most-parking-woes-in-theworld-survey/articleshow/10176038.cms. [Accessed: 28-Feb-2021].

[7] A. Z. M. Tahmidul Kabir, A. M. Mizan, N. Debnath, A. J. Ta-sin, N. Zinnurayen and M. T. Haider, "IoT Based Low Cost Smart Indoor Farming Management System Using an Assistant Robot and Mobile App," 2020 10th Electrical Power, Electronics, Communications, Controls and Informatics Seminar (EECCIS), Malang, Indonesia, 2020, pp. 155-158, doi: 10.1109/EECCIS49483.2020.9263478.

[8] A. Z. M. T. Kabir, A. M. Mizan, P. K. Saha, K. M. M. R. Songlap, A. J. Ta-Sin and N. A. Chisty, "IoT Based Smart Home Automation and Security System Using Mobile App With Assistant Robot for Developing Countries," 2021 International Conference on Electronics, Information, and Communication (ICEIC), Jeju, Korea (South), 2021, pp. 1-4, doi: 10.1109/ICEIC51217.2021.9369770.

[9] P. Melnyk, S. Djahel and F. Nait-Abdesselam, "Towards a Smart Parking Management System for Smart Cities," 2019 IEEE International Smart Cities Conference (ISC2), Casablanca, Morocco, 2019, pp. 542-546, doi: 10.1109/ISC246665.2019.9071740.

[10] G. Şimşek and M. T. Sandıkkaya, "Parking IoT: An IoT Architecture to Collect Availability Data from Parking Lots," 2020 9th Mediterranean Conference on Embedded Computing (MECO), Budva, Montenegro, 2020, pp. 1-5, doi: 10.1109/MECO49872.2020.9134335.

[11] O. Tran Thi Kim, N. H. Tran, C. Pham, T. LeAnh, M. T. Thai and C. S. Hong, "Parking Assignment: Minimizing Parking Expenses and Balancing Parking Demand Among Multiple Parking Lots," in IEEE Transactions on Automation Science and Engineering, vol. 17, no. 3, pp. 1320-1331, July 2020, doi: 10.1109/TASE.2019.2948200.

[12] S. D. Nagowah, H. B. Sta and B. A. Gobin-Rahimbux, "An Ontology for an IoT-enabled Smart Parking in a University Campus," 2019 IEEE International Smart Cities Conference (ISC2), Casablanca, Morocco, 2019, pp. 474-479, doi: 10.1109/ISC246665.2019.9071751.

[13] D. Kim, S. Park, S. Lee and B. Roh, "IoT Platform Based Smart Parking Navigation System with Shortest Route and Anti-Collision," 2018 18th International Symposium on Communications and Information Technologies (ISCIT), Bangkok, Thailand, 2018, pp. 433-437, doi: 10.1109/ISCIT.2018.8587957.

[14] S. Dong, M. Chen, L. Peng and H. Li, "Parking rank: A novel method of parking lots sorting and recommendation based on public information," 2018 IEEE International Conference on Industrial Technology (ICIT), Lyon, France, 2018, pp. 1381-1386, doi: 10.1109/ICIT.2018.8352381.

[15] C. Ajchariyavanich et al., "Park King: An IoT-based Smart Parking System," 2019 IEEE International Smart Cities Conference (ISC2), Casablanca, Morocco, 2019, pp. 729-734, doi: 10.1109/ISC246665.2019.9071721.

[16] S. R. Rizvi, S. Zehra and S. Olariu, "ASPIRE: An Agent-Oriented Smart Parking Recommendation System for Smart Cities," in IEEE Intelligent Transportation Systems Magazine, vol. 11, no. 4, pp. 4861, winter 2019, doi: 10.1109/MITS.2018.2876569.

[17] R. Chen, X. Hu and W. Mu, "Research on parking lot management system based on parking space navigation technology," 2020 IEEE International Conference on Power, Intelligent Computing and Systems (ICPICS), Shenyang, China, 2020, pp. 773-777, doi: 10.1109/ICPICS50287.2020.9202165.

[18] I. Tamam, S. Wang and S. Djahel, "An IoT-based Eco-Parking System for Smart Cities," 2020 IEEE International Smart Cities Conference (ISC2), Piscataway, NJ, USA, 2020, pp. 1-6, doi: 10.1109/ISC251055.2020.9239041.

[19] J. Lin, S. Chen, C. Chang and G. Chen, "SPA: Smart Parking Algorithm Based on Driver Behavior and Parking Traffic Predictions," in IEEE Access, vol. 7, pp. 34275-34288, 2019, doi: 10.1109/ACCESS.2019.2904972.

[20] M. Celaya-Echarri et al., "Building Decentralized Fog ComputingBased Smart Parking Systems: From Deterministic Propagation 
Modeling to Practical Deployment," in IEEE Access, vol. 8, pp. 117666-117688, 2020, doi: 10.1109/ACCESS.2020.3004745.

[21] S. Belkhala, S. Benhadou, and H. Medromi, "Real-time intelligent parking entrance management," International Journal of Advanced Computer Science and Applications(IJACSA), vol. 10, no. 8, 2019. http://dx.doi.org/10.14569/IJACSA.2019.0100854.

[22] Z. Al Taweel, L. Challagundla, A. Pagan and A. -s. Abuzneid, "Smart Parking for Disabled Parking Improvement Using RFID and Database Authentication," 2020 IEEE 6th World Forum on Internet of Things (WFIoT), New Orleans, LA, USA, 2020, pp. 1-5, doi: 10.1109/WFIoT48130.2020.9221069.

[23] B. Jioudi, A. Amari, F. Moutaouakkil, and H. Medromi, "E-parking: Multi-agent smart parking platform for dynamic pricing and reservation sharing service," International Journal of Advanced Computer Science and Applications(IJACSA), vol. 10, no. 11, 2019. http://dx.doi.org/10.14569/IJACSA.2019.0101148.

[24] Y. Xing, J. Li and X. Wang, "Research and Design of Parking Detector Based on NB-IoT and Geomagnetism," 2019 IEEE 2nd International Conference on Information and Computer Technologies (ICICT), Kahului, HI, USA, 2019, pp. 275-279, doi: 10.1109/INFOCT.2019.8711174.

[25] Y. Hou, Y. Zhang, K. Collins and M. Popescu, "Demo Abstract: Building a Smart Parking System on College Campus," 2020 IEEE/ACM Fifth International Conference on Internet-of-Things Design and Implementation (IoTDI), Sydney, NSW, Australia, 2020, pp. 266-267, doi: 10.1109/IoTDI49375.2020.00040.

[26] N. E. Shabasy and M. M. Abdellatif, "IoT for Smart Parking," 2019 International Conference on Advances in the Emerging Computing Technologies (AECT), Al Madinah Al Munawwarah, Saudi Arabia, 2020, pp. 1-6, doi: 10.1109/AECT47998.2020.9194195.

[27] A. Z. M. T. Kabir, N. D. Nath, F. Hasan, R. A. Utshaw and L. Saha, "Automated Parking System with Fee Management Using Arduino," 2019 10th International Conference on Computing, Communication and Networking Technologies (ICCCNT), Kanpur, India, 2019, pp. 16, doi: 10.1109/ICCCNT45670.2019.8944642.

[28] E. Mouhcine, K. Yassine, E. Fazazi, K. Mansouri, and Y. Mohamed, "An internet of things (IOT) based smart parking routing system for smart cities," International Journal of Advanced Computer Science and Applications(IJACSA), vol. 10, no. 8, 2019. http://dx.doi.org/10.14569/IJACSA.2019.0100870.

[29] A. Ampuni, S. Fonataba, A. Fitrianto and G. Wang, "Smart Parking System With Automatic Cashier Machine Utilize the IoT Technology," 2019 International Conference on ICT for Smart Society (ICISS), Bandung, Indonesia, 2019, pp. 1-4, doi: 10.1109/ICISS48059.2019.8969793.

[30] N. Sieck, C. Calpin and M. Almalag, "Machine Vision Smart Parking Using Internet of Things (IoTs) In A Smart University," 2020 IEEE International Conference on Pervasive Computing and Communications Workshops (PerCom Workshops), Austin, TX, USA, 2020, pp. 1-6, 10.1109/PerComWorkshops48775.2020.9156121.

[31] R. Kanan and H. Arbess, "An IoT-Based Intelligent System for RealTime Parking Monitoring and Automatic Billing," 2020 IEEE International Conference on Informatics, IoT, and Enabling Technologies (ICIoT), Doha, Qatar, 2020, pp. 622-626, doi: 10.1109/ICIoT48696.2020.9089589.

[32] A. Mackey, P. Spachos and K. N. Plataniotis, "Smart Parking System Based on Bluetooth Low Energy Beacons With Particle Filtering," in
IEEE Systems Journal, vol. 14, no. 3, pp. 3371-3382, Sept. 2020, doi: 10.1109/JSYST.2020.2968883.

[33] L. F. Herrera-Quintero, J. Vega-Alfonso, D. Bermúdez, L. A. Marentes and K. Banse, "ITS for Smart Parking Systems, towards the creation of smart city services using IoT and cloud approaches," 2019 Smart City Symposium Prague (SCSP), Prague, Czech Republic, 2019, pp. 1-7, doi: 10.1109/SCSP.2019.8805705.

[34] S. Belkhala, S. Benhadou, K. Boukhdir, and H. Medromi, "Smart parking architecture based on multi agent system," International Journal of Advanced Computer Science and Applications(IJACSA), http://dx.doi.org/10.14569/IJACSA.2019.0100349.

[35] Y. Agarwal, P. Ratnani, U. Shah and P. Jain, "IoT based Smart Parking System," 2021 5th International Conference on Intelligent Computing and Control Systems (ICICCS), 2021, pp. 464-470, doi: 10.1109/ICICCS51141.2021.9432196.

[36] M. P. Thakre, P. S. Borse, N. P. Matale and P. Sharma, "IOT Based Smart Vehicle Parking System Using RFID," 2021 International Conference on Computer Communication and Informatics (ICCCI), 2021, pp. 1-5, doi: 10.1109/ICCCI50826.2021.9402699.

[37] S. GokulKrishna, J. Harsheetha, S. Akshaya and D. Jeyabharathi, "An IoT based Smart Outdoor Parking System," 2021 7th International Conference on Advanced Computing and Communication Systems (ICACCS), 2021, pp. 1502-1506, doi: 10.1109/ICACCS51430.2021.9441766.

[38] T. Nguyen et al., "An Adaptive Vision-based Outdoor Car Parking Lot Monitoring System," 2020 IEEE Eighth International Conference on Communications and Electronics (ICCE), 2021, pp. 445-450, doi: 10.1109/ICCE48956.2021.9352090.

[39] D. Annirudh, D. Arun Kumar, A. T. S. R. Kumar and K. R. M. Vijaya Chandrakala, "IoT based Intelligent Parking Management System," 2021 IEEE Second International Conference on Control, Measurement and Instrumentation (CMI), 2021, pp. 67-71, doi: 10.1109/CMI50323.2021.9362845.

[40] U. Mittal, S. Srivastava, and P. Chawla, "Review of different techniques for object detection using deep learning," in Proceedings of the Third International Conference on Advanced Informatics for Computing Research - ICAICR '19, 2019. DOI:https://doi.org/10.1145/3339311.3339357.

[41] A. Z. M. Tahmidul Kabir, A. Mamun Mizan, P. K. Saha, G. Kibria, A. J. Ta-sin and M. Saniat Rahman Zishan, "A Comprehensive Smart IoT Tracker for the Children, Elder, and Luggage With the Assistance of Mobile App," 2020 International Conference on ICT for Smart Society (ICISS), Bandung, Indonesia, 2020, pp. 1-5, doi: 10.1109/ICISS50791.2020.9307591.

[42] A. Z. M. Tahmidul Kabir, A. M. Mizan and T. Tasneem, "Safety Solution for Women Using Smart Band and CWS App," 2020 17th International Conference on Electrical Engineering/Electronics, Computer, Telecommunications and Information Technology (ECTICON), Phuket, Thailand, 2020, pp. 566-569, doi: 10.1109/ECTICON49241.2020.9158134.

[43] A. Z. M. Tahmidul Kabir et al., "An IoT based Intelligent Parking System for the Unutilized Parking Area with Real-Time Monitoring using Mobile and Web Application," 2021 International Conference on Intelligent Technologies (CONIT), 2021, pp. 1-7, doi: 10.1109/CONIT51480.2021.9498286. 